\title{
Microhabitat selection of Discocotyle sagittata (Monogenea: Polyopisthocotylea) in farmed rainbow trout
}

\author{
Miguel Rubio-Godoy \\ Instituto de Ecología, A.C., km 2.5 Carretera Antigua a Coatepec, Xalapa, Veracruz 91070, México
}

Key words: Monogenea, Discocotyle sagittata, microhabitat, trout, Oncorhynchus mykiss

\begin{abstract}
Microhabitat preference of the monogenean Discocotyle sagittata (Leuckart, 1842) was determined in late spring and late autumn in rainbow trout, Oncorhynchus mykiss (Walbaum), reared in the Isle of Man, UK. Discocotyle sagittata exhibits a preference for attachment to anterior gill arches: $29 \%$ of all worms occurred on gill arch I, $28 \%$ on II, $25 \%$ on III and $18 \%$ on IV. This distribution pattern on the introduced salmonid species is the same as reported for its native European host, the brown trout Salmo trutta (L.). Previous experimental work suggested that invasion is a passive process followed by post-invasion migration to anterior gill arches; the present work provides evidence of equivalent site selection taking place in fishes maintained under conditions promoting continuous reinfection in aquaculture. Migration may be density-dependent, since a significant inverse association was found between the intensity of mature parasites and their proportion on anteriormost gill arch I.
\end{abstract}

Microhabitat preference of gill-parasitic worms is usually determined from a random sample of wild fishes, including hosts of different ages, captured at various times of the year and, frequently, harbouring parasites of different species and developmental stages. Gill-infecting monogeneans commonly exhibit very precise site specificity (Euzet and Combes 1998, Kearn 1998); for instance, Diclidophora merlangi occurs most frequently on the first gill arch (g.a.) of whiting Gadus merlangus (Llewellyn 1956, Arme and Halton 1972), $D$. luscae on the second and third g.a. of pouting G. luscus (Llewellyn 1956); Diplozoon paradoxum favours the first two g.a. of roach Rutilus rutilus (Owen 1963) and bream Abramis brama (Wiles 1968); and Dactylogyrus amphibothrium prefers the second and third g.a. of ruffe Gymnocephalus cernua (Wootten 1974). Several possible explanations for this have been put forward: for instance, variation of worm distribution on the gills in response to water currents (Llewellyn 1956, Paling 1969) or to differences in area between g.a. (Buchmann 1989), aggregation of parasites for mating (Rohde et al. 1995), avoidance of interspecific competition (Šimková et al. 2000), and migration driven by host immunity (Buchmann and Bresciani 1998). Several of these factors may act synergistically, as suggested by recent studies which considered the effect of two factors on microhabitat preference, water current and gill area (Gutiérrez and Martorelli 1999).

Discocotyle sagittata (Leuckart, 1842) Diesing, 1850 shows preference for attachment to the two most anterior g.a. in brown trout, Salmo trutta (L.), a native European host (Llewellyn 1956, Paling 1969, Slinn 1963). Experimental trickle and single infection of rainbow trout, Oncorhynchus mykiss (Walbaum), suggested that $D$. sagittata invades the gills passively with the respiratory current, and that developing worms migrate anteriorly post-invasion to, presumably, preferred gill arches (Rubio-Godoy and Tinsley 2002). In this study, I report the microhabitat preference of $D$. sagittata in farmed O. mykiss, an introduced species reared extensively in Europe. In aquaculture, parasite infection may occur continuously during favourable conditions and different cohorts of parasites develop side-by-side on the same gills (Rubio-Godoy and Tinsley 2008b). Precise data were available on fish age, season of sample collection and age and abundance of distinct parasite developmental stages, and I assessed whether these variables influenced the incidence of worms on gill arches.

\section{MATERIALS AND METHODS}

Fish. Rainbow trout (O. mykiss) samples were obtained on the Isle of Man, UK, from two fish farms (farm 1 in the SouthWest, farm 2 in the North-East) that have experienced $D$. sagittata-related mortality (Gannicott 1997, Rubio-Godoy and Tinsley 2008a). Farms were visited in late spring (mid-late May) and late autumn (late November) in 1999, 2000 and 2001, during general fish health inspections carried out for the Department of Agriculture, Fisheries and Forestry (Isle of Man Government). Trout were anaesthetized terminally with MS222 (0.05\% solution buffered to $\mathrm{pH} 7.0)$ and dissected for general bacteriological/parasitological tests. I am confident that the few minutes of exposure to MS222 did not affect the numbers of $D$. sagittata recovered from anaesthetized hosts: dislodged worms were never found in the MS222 solution after many hundreds of terminal anaesthetizations. Fish-ofthe-year $(0+)$, one-year-old $(1+)$ and two-year-old $(2+)$ trout were measured (fork length) and weighed, and their gill arches (g.a.) were removed and preserved in $10 \%$ formalin for later microscopic analysis.

Parasites. Individual preserved g.a. were examined under the dissecting microscope. The number of parasites per g.a. (right and left) was recorded, and their developmental stages were determined based on the number of pairs of clamps (p.c.) present on the haptor: values ranged from 1 for freshly- 
hatched worms with 1 p.c. to 4.5 for sexually mature parasites with 4 p.c. (Gannicott 1997, Rubio-Godoy and Tinsley 2002). Intermediate values were assigned when new clamps had begun developing on the haptor, reflecting the addition of clamps as development proceeds. Parasites were assigned to three developmental categories: juvenile worms with 1 to 2 p.c., intermediate stages with 2.5 to 3.5 p.c., and mature individuals (4 p.c.).

Statistical analysis. The use of parasitological terms follows Bush et al. (1997). All calculations, except comparisons of mean parasite abundance between g.a., were performed with SPSS for Windows 14.0. To contrast worm burdens between g.a., mean parasite abundances were calculated and compared with the software Quantitative Parasitology 3.0 using bootstrap 2-sample t-tests with 2000 replications (Rózsa et al. 2000). To check whether parasite burdens differed between right and left g.a., data from the three successive years were pooled by fish age class and date of collection (May or November), and mean parasite abundances were calculated and compared. Worm position on the gill apparatus was analyzed with chi-squared tests. First, since formalin fixation resulted in some dislodged worms, $\chi^{2}$ tests were used to compare parasite distribution in samples without unattached specimens with that in samples containing a proportion of detached worms (proportions of dislodged worms ranged $1-20 \%$, with the higher percentages occurring in samples with lower parasite intensities); no significant differences were found and the samples were thus pooled for positional analyses (data not shown). Second, $\chi^{2}$ tests were used to compare worm distribution on the respiratory apparatus between farms. Finally, $\chi^{2}$ tests were used to compare the observed parasite localization with the predicted distribution based on relative water flows over each g.a., as determined by Paling (1968) using Anodonta cygnea glochidia: arch I $=24.2 \%$ of total water flow; arch II = 30.0\%; arch III = 28.2\%; arch IV = 17.6\%. The overall microhabitat preference was determined considering the position on the g.a. of all parasites recovered from all fish. Microhabitat preference was then established considering juvenile, intermediate and mature worms as separate groups; this was done for each fish year class and sampling season.
The association between the intensity of mature parasites and the proportion of mature parasites on g.a. I was assessed by a Spearman's rank correlation.

\section{RESULTS}

No significant difference was found when contrasting the mean abundance of $D$. sagittata on the right and left g.a. on different age classes of $O$. mykiss (Table 1; bootstrap t-tests; n.s.). Therefore, numbers of worms recovered from each pair of g.a. were pooled. Despite differences in mean parasite abundance (Table 1), worm distribution on the g.a. followed similar patterns in both farms. For example, in 1+ and 2+ trout sampled in November (Fig. 1), microhabitat preference was not significantly different between farms in five instances out of six ( $\chi^{2}$ tests; n.s.). The only case where a significant difference was recorded between farms is that of intermediate worms on $1+$ fish $\left(\chi^{2}\right.$ test, $\left.P=0.013\right)$. However, in both farms, intermediate stage parasites occurred most frequently on the anterior half of the respiratory apparatus and g.a. I had significantly higher burdens than g.a. IV. Thus, samples from both farms were considered to represent the same trend and were combined for further analyses.

In May samples, parasite distribution reflected an overall preference for the anterior gill arches: $30.6 \%$ of all worms were located on g.a. I, $27.3 \%$ on II, $22.4 \%$ on III and $19.7 \%$ on IV. 0+ fish were not infected in May. Limited numbers of intermediate stage worms were found on 1+ and 2+ trout, and these mainly occurred anteriorly (Fig. 2). Mature parasites exhibited a preference for g.a. I and II (Fig. 2): in both $1+$ and 2+ fish, parasite abundances in g.a. I and II were not significantly different from each other, but were significantly higher than those on g.a. III and IV (bootstrap t-tests; $P$ values ranging from 0.0305 to $<0.0001$ ). The proportion of mature worms occurring on g.a. I was higher in $1+$ fish (45.7\%; mature parasite mean intensity \pm SE $4.03 \pm 0.56$ worms/host) than in $2+$ fish (38.6\%; intensity

Table 1. Mean abundance of Discocotyle sagittata on the gills of rainbow trout (Oncorhynchus mykiss) raised in different farms.

\begin{tabular}{|c|c|c|c|c|}
\hline \multirow[b]{2}{*}{ Oncorhynchus mykiss } & \multirow[b]{2}{*}{$\mathrm{n}$} & & \multicolumn{2}{|c|}{ Mean worms/host \pm SE } \\
\hline & & & right gill arches & left gill arches \\
\hline \multirow[t]{3}{*}{$1+$ May } & 120 & Mean & $1.73 \pm 0.27$ & $1.83 \pm 0.30$ \\
\hline & & Farm 1 & $2.57 \pm 0.47$ & $2.64 \pm 0.52$ \\
\hline & & Farm 2 & $0.86 \pm 0.18$ & $1.00 \pm 0.23$ \\
\hline \multirow[t]{3}{*}{ 2+ May } & 70 & Mean & $28.21 \pm 3.43$ & $29.06 \pm 3.66$ \\
\hline & & Farm 1 & $37.56 \pm 5.79$ & $39.32 \pm 6.15$ \\
\hline & & Farm 2 & $16.52 \pm 1.25$ & $16.25 \pm 1.37$ \\
\hline \multirow[t]{3}{*}{ 0+ November } & 120 & Mean & $0.52 \pm 0.09$ & $0.61 \pm 0.09$ \\
\hline & & Farm 1 & $0.05 \pm 0.03$ & $0.13 \pm 0.04$ \\
\hline & & Farm 2 & $0.98 \pm 0.15$ & $1.08 \pm 0.15$ \\
\hline \multirow[t]{3}{*}{$1+$ November } & 109 & Mean & $27.23 \pm 3.57$ & $26.61 \pm 3.30$ \\
\hline & & Farm 1 & $40.55 \pm 7.42$ & $38.45 \pm 6.83$ \\
\hline & & Farm 2 & $16.35 \pm 1.18$ & $16.95 \pm 1.28$ \\
\hline \multirow[t]{3}{*}{ 2+ November } & 60 & Mean & $60.56 \pm 7.08$ & $61.14 \pm 7.72$ \\
\hline & & Farm 1 & $57.15 \pm 13.85$ & $65.10 \pm 16.76$ \\
\hline & & Farm 2 & $62.83 \pm 7.54$ & $58.50 \pm 6.69$ \\
\hline
\end{tabular}



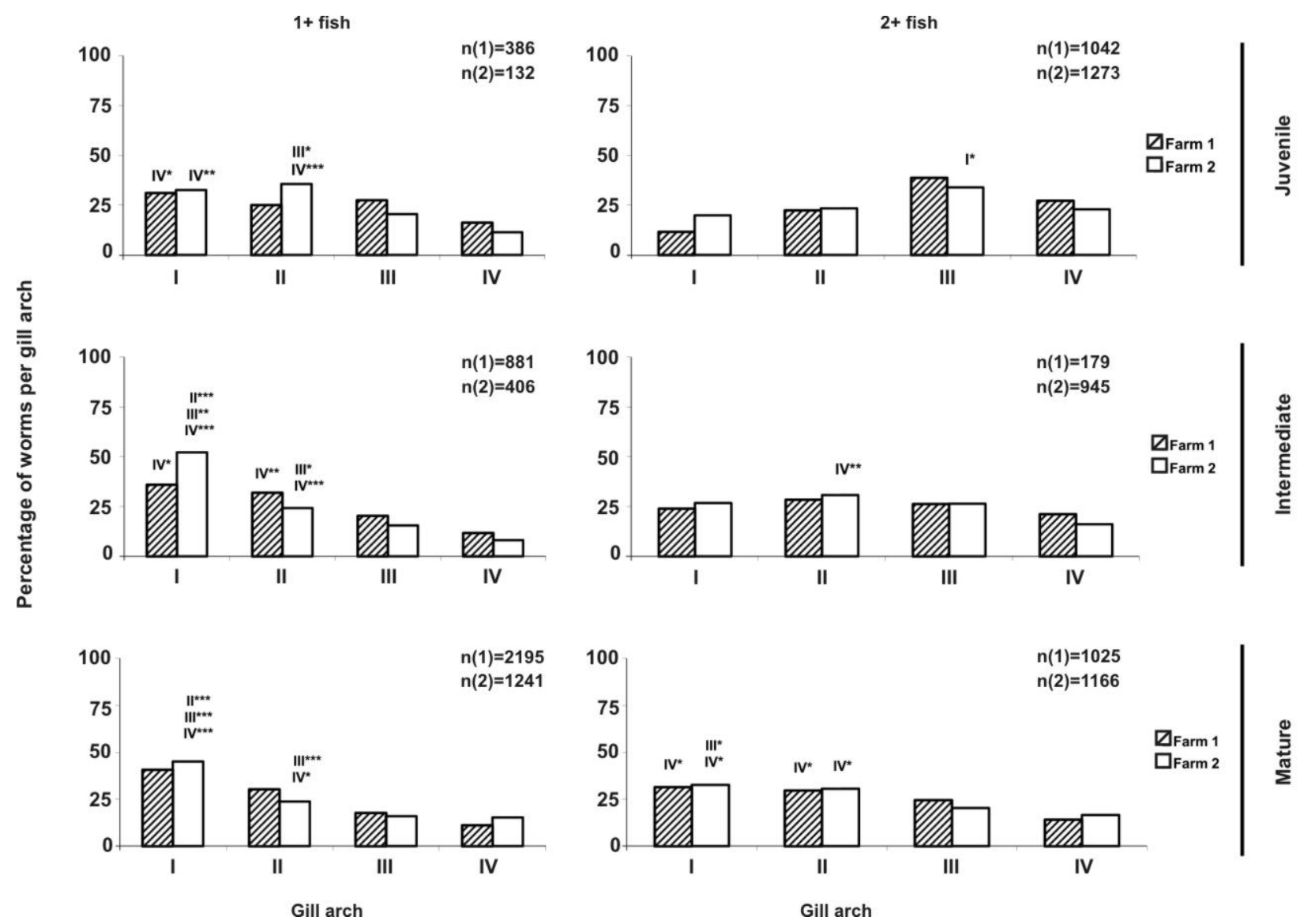

Fig. 1. Distribution of Discocotyle sagittata on the gill arches of rainbow trout (Oncorhynchus mykiss) in November. The distribution on the gill arches and sample size in the two farms $[\mathrm{n}(1), \mathrm{n}(2)]$ are shown for juvenile (1-2 pairs of clamps), intermediate (2.5-3.5 pairs of clamps) and mature (4 pairs of clamps) parasites. Roman numerals above each bar indicate gill arches that had significantly different parasite abundances (bootstrap t-tests; significance levels: ${ }^{*} P=0.05$; $* * P=0.001$; ${ }^{* *} P=0.0001$ ).

$25.82 \pm 2.91$ worms/host). Usually, very limited numbers of juvenile parasites were found in trout sampled in May. However, in 2+ O. mykiss sampled at farm 1 in May 2000, juvenile worms with 1 p.c. accounted for over one half of the total burdens recorded, indicating mass infection had recently taken place. In these fish $(\mathrm{n}=22)$, most mature parasites (intensity $70.4 \pm 11.84$ worms/host) were located anteriorly (31.1\% on g.a. I, $32.0 \%$ on II, $19.4 \%$ on III and $17.5 \%$ on IV) and the majority of juveniles (95.1 \pm 8.55 worms/host) posteriorly $(14.9 \%$ on g.a. I, $14.9 \%$ on II, $33.7 \%$ on III and $36.5 \%$ on IV). In these mass-infected fish, juvenile parasite distribution was not significantly associated to relative water flows ( $\chi^{2}$ test; $P<0.0001$ ) and their abundance was significantly greater in the posterior g.a. III and IV than in the anterior g.a. (bootstrap t-tests; $P<0.0001)$. The same pattern of juvenile parasite distribution was determined in fish with both high and low abundances of mature worms (range 2-214 mature worms/host).

In November samples, there was also an overall preference for the anterior arches: $28.2 \%$ of all worms occurred on g.a. I, $28.6 \%$ on II, $25.8 \%$ on III and $17.4 \%$ on IV. Limited numbers of parasites were found in $0+$ fish (Table 1), and these mainly occurred anteriorly (Fig. 3). In total, $60.3 \%$ of all mature worms found on $0+$ fish occurred on g.a. I, which had significantly higher mean parasite abundance than all other arches (bootstrap t-tests; $P$ value range 0.0160 to 0.0010 ); mean intensity was $1.84 \pm 0.17$ mature worms/host. In $1+O$. mykiss, higher parasite burdens were recorded (mean abundance ca. 50 worms/host; Table 1). In these fish, the distribution of juvenile worms was significantly associated with the relative amounts of water flowing over each g.a. ( $\chi^{2}$ test; n.s.). Intermediate stage and mature worms tended to occur anteriorly, with g.a. I harbouring $35.8 \%$ of developing and $38.7 \%$ of mature worms. The abundance of both intermediate stage and mature worms on g.a. I was significantly higher than that on g.a. IV (bootstrap t-tests; $P$ value range 0.0485 to 0.0065 ), but not significantly different to that on g.a. II. In 2+ trout, parasite abundance was approximately 120 worms/host (Table 1). In this group, most juvenile worms occurred on g.a. III, which harboured significantly higher burdens than g.a. I (bootstrap t-test; $P=0.0475)$. The distribution of both intermediate and 

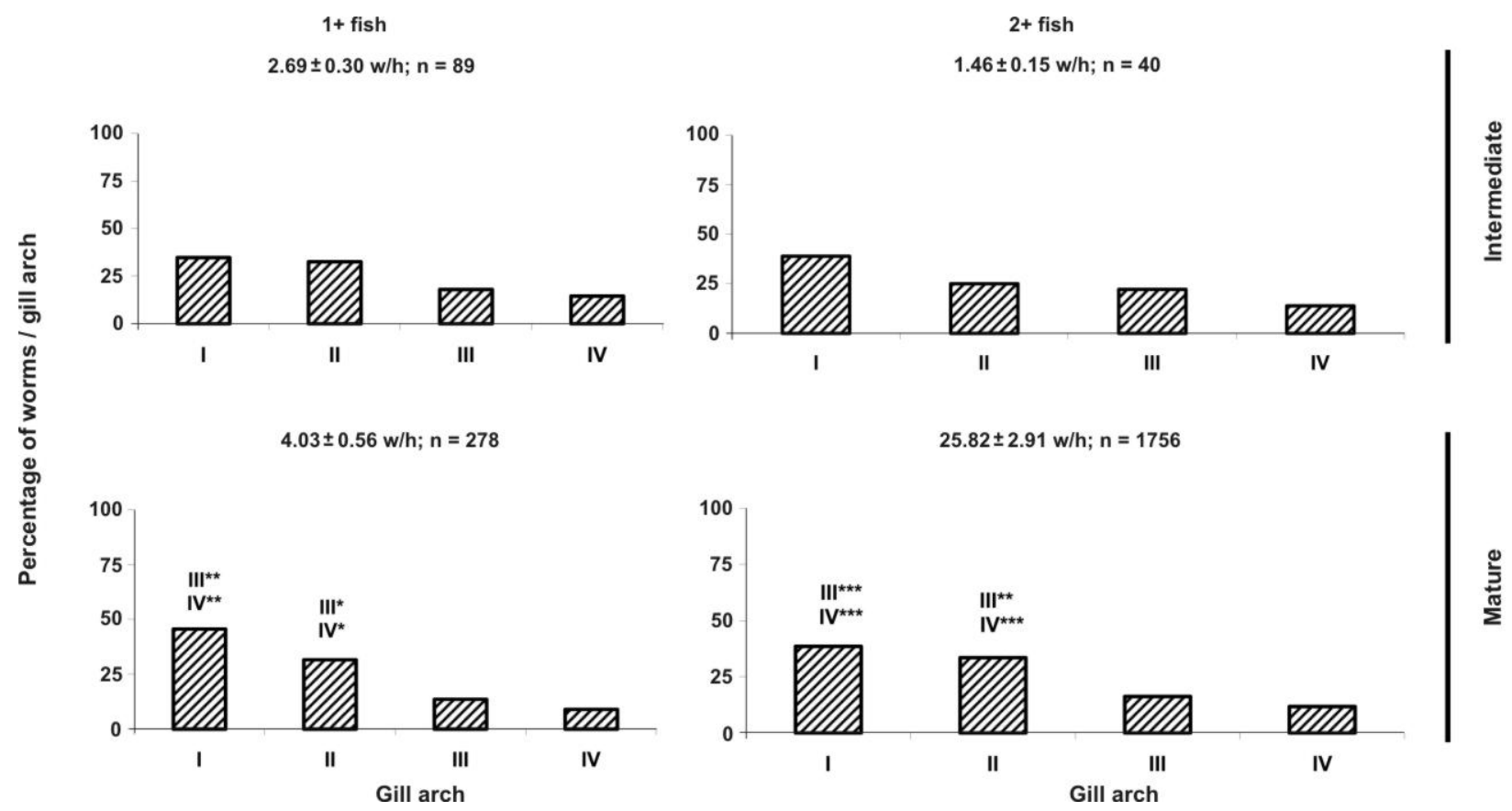

Fig. 2. Distribution of Discocotyle sagittata on the gill arches of rainbow trout (Oncorhynchus mykiss) in May. The distribution on the gill arches, mean intensity and sample size are shown for intermediate (2.5-3.5 pairs of clamps) and mature (4 pairs of clamps) parasites. Roman numerals above each bar indicate gill arches that had significantly different parasite abundances (bootstrap t-tests; significance levels: ${ }^{*} P=0.05 ; * * P=0.001$; *** $P=0.0001$ ).

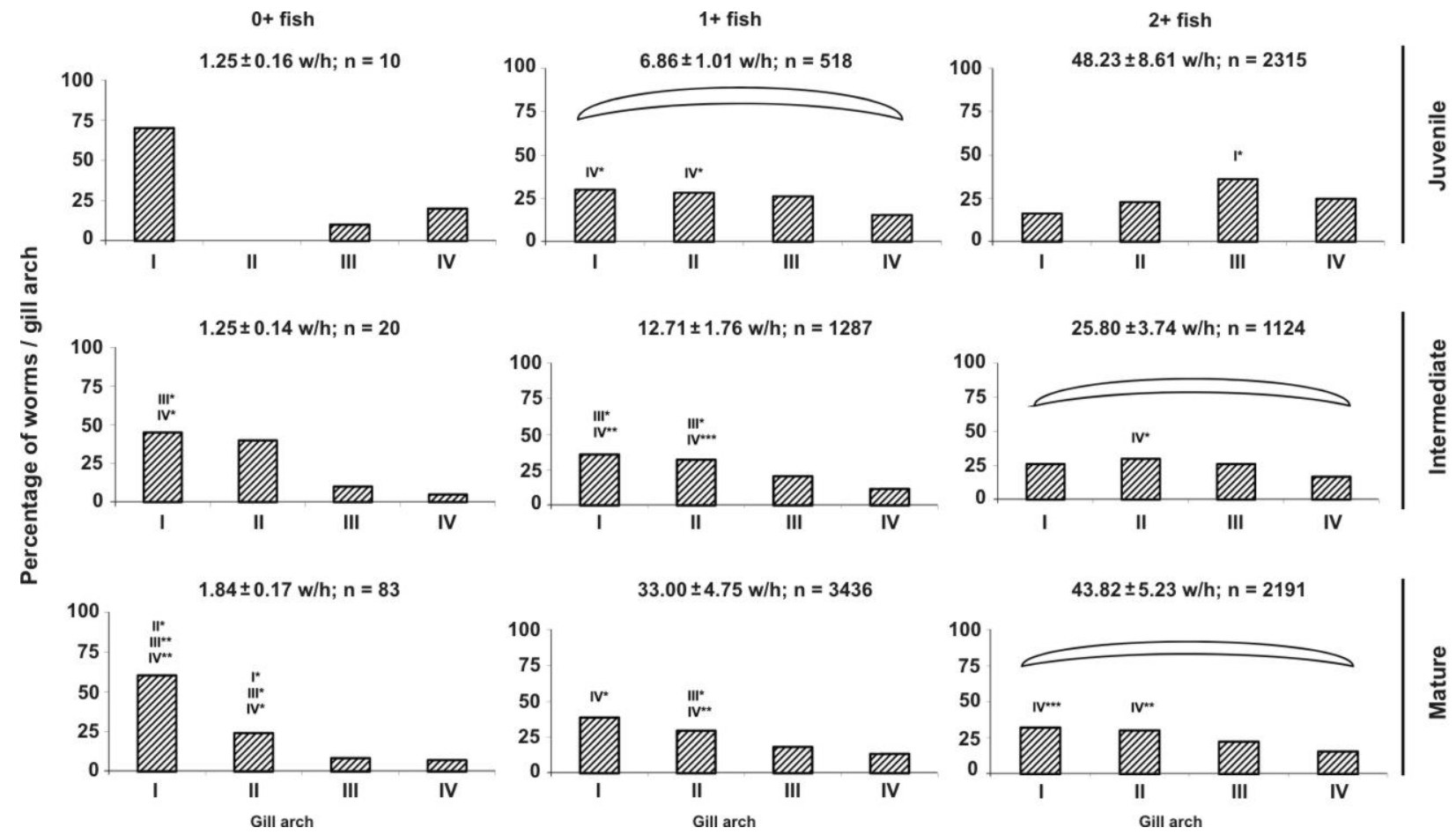

Fig. 3. Distribution of Discocotyle sagittata on the gill arches of rainbow trout (Oncorhynchus mykiss) in November. The distribution on the gill arches, mean intensity and sample size are shown for juvenile (1-2 pairs of clamps), intermediate (2.5-3.5 pairs of clamps) and mature (4 pairs of clamps) parasites. Roman numerals above each bar indicate gill arches that had significantly different parasite abundances (bootstrap t-tests; significance levels: $* P=0.05 ; * * P=0.001$; *** $P=0.0001$ ). The elongated shape indicates that the distribution of $D$. sagittata on the gill arches was not significantly different from that predicted by relative water flows over the respiratory apparatus $\left(\chi^{2}\right.$ test). 
mature worms was significantly associated with respiratory flows ( $\chi^{2}$ test; n.s.). Arches I and II had significantly higher abundance of mature parasites than g.a. IV (bootstrap t-tests; $P$ value range 0.0010 to 0.0005 ), with $32.1 \%$ and $30.1 \%$ of all worms found, respectively.

Considering all fish, the combined data confirmed the indications of the separate seasonal analyses: $29 \%$ of all worms recovered occurred on g.a. I, 28.2\% on II, $24.6 \%$ on III and $18.2 \%$ on IV. A significant negative correlation was found between the proportion of mature parasites occurring on g.a. I and mature parasite intensity (Spearman's rank correlation coefficient rho = $-0.3412 ; P<0.0001)$.

\section{DISCUSSION}

Previous experimental studies suggest that Discocotyle sagittata invades the respiratory apparatus of rainbow trout, O. mykiss, passively as 1 month postinfection the two central g.a. harboured the majority of parasites. This correlated with the proportion of the respiratory current flowing over each arch (Rubio-Godoy and Tinsley 2002), as determined using glochidia of the freshwater mussel Anodonta cygnea (Paling 1968). However, as parasites developed, their distribution gradually decreased in g.a. III and IV and increased in g.a. I and II, suggesting that worms migrate following initial attachment (Rubio-Godoy and Tinsley 2002). In the present study of farmed rainbow trout, $D$. sagittata shows an overall preference for attachment to the two most anterior g.a. This is consistent with its microhabitat distribution on two forms of $S$. trutta, wild sea trout and brown trout (Llewellyn 1956, Paling 1969, Slinn 1963). These previous reports were based on relatively low intensities of infection characteristically encountered in the wild. By contrast, this survey shows the distribution of $D$. sagittata based on significantly higher burdens of parasites found in affected fish farms. These data represent three distinct points in the annual transmission cycle, which is mainly driven by temperature (Rubio-Godoy and Tinsley 2008b). The first point is illustrated by samples collected in late spring (May in this study), which typically show parasites that invaded before the preceding winter and are now predominantly adult. The second point occurs when transmission begins as water temperatures increase, with infections showing the distribution of recently-invaded worms cooccurring with existing parasite burdens. Finally, in late autumn (November samples), data illustrate the distribution of new recruits in the absence of established burdens (in $0+$ fish) as well as the maximum interaction state showing the location of worm attachment after many months of parasite accumulation $(1+$ and $2+$ trout).

Discocotyle sagittata are relatively long-lived worms that survive at least one year, over-wintering on the gills (Chubb 1977, Valtonen et al. 1990, Rubio-Godoy and Tinsley 2008b). The "settled" distribution of adult, over-wintered parasites found in this study in May suggests that the anterior half of the respiratory apparatus is their preferred attachment site in farmed O. mykiss, with arches I and II harbouring comparable burdens. In May 2000, 2+ rainbow trout in farm 1 concurrently harboured high numbers of mature and freshly-attached parasites, indicating a recent massive infection (RubioGodoy and Tinsley 2002, 2008b). As in other May samples in this study, mature worms in these fish occurred preferentially on the two anterior arches: $31.1 \%$ on g.a. I, $32.0 \%$ on g.a. II. Assuming passive invasion, it would be expected that $24.2 \%$ of worms would occur on g.a. I, $30.0 \%$ on II, $28.2 \%$ on III and $17.6 \%$ on IV (Paling 1969). The distribution of recently-attached worms resulting from mass invasion over a limited period in this study does not concur with the predictions of passive invasion, as juveniles occurred most frequently on g.a. III (33.7\%) and IV (36.5\%). The presence of mature parasites on the anterior g.a. may have inhibited oncomiracidial attachment during invasion, increasing the proportion of juveniles on the posterior arches. However, this mainly posterior distribution of juveniles was determined in fish with both high and low intensities of mature parasites.

November samples show the g.a. distribution of D. sagittata following several months of accumulation of invading worms: this represents the maximum interaction state between different developmental stages of the parasite. In laboratory experimental infections of naïve trout, Rubio-Godoy and Tinsley (2002) considered that $D$. sagittata migrated to more anterior g.a. as they develop. One-year-old fish sampled in November provide evidence that post-invasion migration may occur in circumstances of heavy infection in farmed trout. Thus, the distribution of juvenile worms could be explained by relative water flows over the respiratory apparatus (in the absence of pre-existing infection), but intermediate and mature stages tended to occur progressively on the more anterior arches; the increased proportion of anterior worms is particularly noticeable on g.a. I, harbouring $35.8 \%$ of intermediate and $38.7 \%$ of mature worms. Other examples of post-invasion migration of gill-infecting monogeneans include Neoheterocotyle rhinobatidis in common shovelnose ray, Rhinobatos typus (Chisholm and Whittington 1998); Haliotrema sp. in damselfish, Dascyllus aruanus (Lo and Morand 2000); and Dactylogyrus spp. in roach, $R$. rutilus fry (Bagge and Valtonen 1999). It has been suggested that changes in haptoral structures occurring at different stages in the development of monopisthocotylean parasites modify their ability to withstand water currents and enable them to attach to different parts of the gills (Chisholm and Whittington 1998). Likewise, the addition of clamps to the haptor of the polyopisthocotylean $D$. sagittata as development proceeds would progressively enhance the parasites' grip on the gills and facilitate migration; this would be consistent with the observation that worms tend to stay in the original attachment site until they have grown 2-3 pairs of clamps (RubioGodoy and Tinsley 2002).

In the present study, migration of developing parasites to anterior g.a. may be hindered by the presence of 
established worms. At the low burdens detected in $0+$ fish in November, which were uninfected at the beginning of the transmission season, $60.3 \%$ of mature worms occurred on g.a. I. In older fish, in which burdens included over-wintered parasites and worms acquired during the immediately preceding summer, mature parasites also occurred most often anteriorly, but their proportion on g.a. I decreased with increasing parasite abundance: $38.7 \%$ at ca. 50 worms/host in $1+$ fish and 32.1\% at ca. 120 worms/host in 2+ fish (Fig. 3). The significant negative correlation found between mature parasite intensity and the proportion of mature worms on anteriormost g.a. I suggests that post-invasion migration is density-dependent: this would explain why, at higher parasite burdens, the distribution of intermediate stage and mature worms on the g.a. of $2+$ fish reflects relative water flows (Fig. 3). Microhabitat saturation might also partially account for the posterior distribution of juvenile parasites in 2+ fish (both massinfected May and November samples), which occurred most frequently on g.a. III and IV: it is conceivable that oncomiracidia could not settle on anterior arches already occupied by relatively high intensities of intermediate and mature worms. Density-dependent migration has also been documented in the monogeneans Polylabris mamaevi and Tetrancistrum nebulosi, which preferentially occur on g.a. I on the gills of mottled spinefoot, Siganus fuscescens, but progressively tend to occur on posterior arches as intensity increases (Yang et al. 2006).

As shown in Table 1, parasite burdens tend to increase with increasing fish age. Significant positive associations were found between host length and $D$. sagittata intensities in $0+$ and $1+$ fish (Rubio-Godoy and Tinsley 2008b). Positive correlations between the abundance of gill-infecting monogeneans and host length have been proposed to be partially related to increases in gill surface available for attachment as fish grow (Rohde et al. 1995). However, no significant host size/worm burden association was found for 2+ fish, and there is evidence that farmed rainbow trout might develop acquired immunity to $D$. sagittata (Rubio-
Godoy et al. 2003, Rubio-Godoy and Tinsley 2008b). Further studies would need to consider other factors affecting microhabitat preference of $D$. sagittata; these could include assessments of the relative influences of available attachment surface (Buchmann 1989, Gutiérrez and Martorelli 1999), parasite intensity (Lo and Morand 2000) and host immunity (Buchmann and Bresciani 1998) on site selection.

This work demonstrates that $D$. sagittata exhibits the same preference for attachment to the two anterior gill arches in both rainbow trout (O. mykiss), an introduced fish species, and in its native European host, brown trout (S. trutta). Several other gill-infecting monogeneans also show preference for anterior arches, including Diclidophora merlangi, which occurs most frequently on the first g.a. of whiting Gadus merlangus (Llewellyn 1956, Arme and Halton 1972). The similar microhabitat preference of $D$. merlangi and $D$. sagittata concurs with evidence based on their shared morphological characters that these are marine and freshwater equivalents of one another (Cable et al. 1996). The present study supports previous findings that invasion of the gills may be a passive process, and indicates that $D$. sagittata migrates post-invasion to presumably preferred locations within its habitat. This migration is less extensive than that shown for monopisthocotyleans by Euzet and Combes (1998) and may be sensitive to, among other possible factors, microhabitat saturation.

Acknowledgements. I am grateful to several people: Richard Tinsley (University of Bristol) for guidance during the performance of this work and comments on the manuscript; John Ballard and Ken Jervis (Isle of Man) for access to infected fish; Roger Sweeting (Freshwater Biological Association) and the late David McGregor (CEFAS Weymouth) for sharing their fish samples with me; Les and the late Pam Kneale (Isle of Man) for their support during fieldwork. I was supported by postgraduate scholarships from the Mexican National Council for Science and Technology (CONACYT) and Universities UK (formerly Committee of Vice-Chancellors and Principals), and carried out the present work at the School of Biological Sciences, University of Bristol, UK.

\section{REFERENCES}

ARME C., HALTON D.W. 1972: Observations on the occurrence of Diclidophora merlangi (Trematoda: Monogenea) on the gills of whiting, Gadus merlangus. J. Fish Biol. 4: 27-32.

BAGGE A.M., VALTONEN E.T. 1999: Development of monogenean communities on the gills of roach fry (Rutilus rutilus). Parasitology 118: 479-487.

BUCHMANN K. 1989: Microhabitats of monogenean gill parasites of European eel (Anguilla anguilla). Folia Parasitol. 36: 321329.

BUCHMANN K., BRESCIANI J. 1998: Microenvironment of Gyrodactylus derjavini on rainbow trout Oncorhynchus mykiss: association between mucous cell density in skin and site selection. Parasitol. Res. 84: 17-24.

Bush A.O., LAFFERTY K.D., LOTZ J.M., SHOSTAK A.W. 1997 Parasitology meets ecology on its own terms: Margolis et al. revisited. J. Parasitol. 83: 575-583.
CABLE J., MARKS N.J., HALTON D.W., SHAW C., JOHNSTON C.F., Tinsley R.C., GANNICOTT A.M. 1996: Cholinergic, serotoninergic and peptidergic components of the nervous system of Discocotyle sagittata (Monogenea: Polyopisthocotylea). Int. J. Parasitol. 26: 1357-1367.

Chisholm L.A., WhitTINGTON I.D. 1998: Morphology and development of the haptors among the Monocotylidae (Monogenea). Hydrobiologia 383: 251-261.

CHUBB J.C. 1977: Seasonal occurrence of helminths in freshwater fishes. Part 1. Monogenea. Adv. Parasitol. 15: 133-199.

EUZET L., COMBES C. 1998: The selection of habitats among the Monogenea. Int. J. Parasitol. 28: 1645-1652.

GANNICOTT A.M. 1997: The biology of Discocotyle sagittata (Monogenea) infecting trout. Ph.D. Thesis, University of Bristol, Bristol, 312 pp. 
GUTIÉRREZ P.A., MARTORELLI S.R. 1999: Hemibranch preference by freshwater monogeneans a function of gill area, water current, or both? Folia Parasitol. 46: 263-266.

KEARN G.C. 1998: Parasitism and the Platyhelminths. Chapman \& Hall, London, 544 pp.

Lo C.M., MORAND S. 2000: Spatial distribution and coexistence of monogenean gill parasites inhabiting two damselfishes from Moorea island in French Polynesia. J. Helminthol. 74: 329-336.

LLEWELLYN J. 1956: The host-specificity, micro-ecology, adhesive attitudes, and comparative morphology of some trematode gill parasites. J. Mar. Biol. Assoc. 35: 113-127.

OWEN I.L. 1963: The attachment of the monogenean Diplozoon paradoxum to the gills of Rutilus rutilus L. Micro-habitat and adhesive attitude. Parasitology 53: 455-461.

PALING J.E. 1968: A method of estimating the relative volumes of water flowing over the different gills of a freshwater fish. J. Exp. Biol. 48: 533-544.

PALING J.E. 1969: The manner of infection of trout gills by the monogenean parasite Discocotyle sagittata. J. Zool. 159: 293309.

ROHDE K., HAYWARD C., HEAP M. 1995: Aspects of the ecology of metazoan ectoparasites of marine fishes. Int. J. Parasitol. 25: 945-970.

RÓZSA L., REICZIGEL J., MAJOROS G. 2000: Quantifying parasites in samples of hosts. J. Parasitol. 86: 228-232.

RUBIO-GODOY M., SIGH J., BUCHMANN K., TINSLEY R.C. 2003: Antibodies against Discocotyle sagittata (Monogenea) in farmed trout. Dis. Aquat. Org. 56: 181-184.

RuBio-GodOY M., TINSLEY R.C. 2002: Trickle and single infection with Discocotyle sagittata (Monogenea: Polyopistho- cotylea): effect of exposure mode on parasite abundance and development. Folia Parasitol. 49: 269-278.

RUBIO-GODOY M., TINSLEY R.C. 2008a: Recruitment and effects of Discocotyle sagittata (Monogenea) infection on farmed trout. Aquaculture 274: 15-23.

RUBIO-GODOY M., TINSLEY R.C. 2008b: Transmission dynamics of Discocotyle sagittata (Monogenea) in farmed rainbow trout interpreted from parasite population age structure. Aquaculture 275: 34-41.

ŠIMKOVÁ A., DESDEVISES Y., GELNAR M., MORAND S. 2000: Coexistence of nine gill ectoparasites (Dactylogyrus: Monogenea) parasitising the roach (Rutilus rutilus L.): history and present ecology. Int. J. Parasitol. 30: 1077-1088.

SLINN D.J. 1963: Occurrence of Discocotyle sagittata on sea trout. Nature 197: 306

VALtonen E.T., Prost M., RAHKONEN R. 1990: Seasonality of two gill monogeneans from two freshwater fish from an oligotrophic lake in Northeast Finland. Int. J. Parasitol. 20: 101-107.

WILES M. 1968: The occurrence of Diplozoon paradoxum Nordmann, 1832 (Trematoda: Monogenea) in certain waters of northern England and its distribution on the gills of certain Cyprinidae. Parasitology 58: 61-70.

WOOTTEN R. 1974: The spatial distribution of Dactylogyrus amphibothrium on the gills of the ruffe Gymnocephalus cernua and its relation to the relative amounts of water passing over the parts of the gills. J. Helminthol. 48: 167-174.

YANG T., LIU J., GIBSON D.I., DONG A. 2006: Spatial distributions of two species of monogeneans on the gills of Siganus fuscescens (Houttuyn) and their seasonal dynamics in caged versus wild-caught hosts. J. Parasitol. 92: 933-940. 